\title{
An ocean model's response to North Atlantic Oscillation-like wind forcing
}

\author{
Martin Visbeck, Heidi Cullen, Gerd Krahmann, and Naomi Naik
}

Lamont-Doherty Earth Observatory of Columbia University, Palisades, New York

\begin{abstract}
The response of the Atlantic Ocean to North Atlantic Oscillation (NAO)-like wind forcing was investigated using an ocean-only general circulation model coupled to an atmospheric boundary layer model. A series of idealized experiments was performed to investigate the interannual to multi-decadal frequency response of the ocean to a winter wind anomaly pattern. Overall, the strength of the SST response increased slightly with longer forcing periods. In the subpolar gyre, however, the model showed a broad response maximum in the decadal band (12-16 years).
\end{abstract}

\section{Introduction}

We know from observations that the North Atlantic Oscillation (NAO) is the dominant, large-scale, extratropical teleconnection pattern in the Atlantic sector [Bjerknes, 1964; Hurrell, 1995]. Its phase is indicated by the NAO index (NAOI), which measures the pressure difference between Portugal and Iceland. It is therefore related to the strength and position of maximum surface westerlies across the Atlantic and into Europe [van Loon and Rogers, 1978]. During the positive NAO phase relatively warm and moist air masses are advected by stronger than usual winter storms into northern Europe. At the same time temperatures in northeastern Canada and Greenland are below normal and precipitation in the Mediterranean Sea region is reduced. The NAO index itself exhibits a somewhat red spectrum with an indication for enhanced energy in the interannual and decadal frequency bands [Hurrell and van Loon, 1997]. However, the records at hand are too short (130 years) to prove the significance of the peaks, which could be the signature of a two way coupled atmosphere-ocean mode. All we might be seeing is a particular realization of a white noise atmosphere which initiates a red noise ocean response.

An alternative approach to statistical data analysis is to utilize ocean and atmosphere models to investigate the physical mechanisms of Atlantic climate variability. Some of the global atmosphere-ocean models have produced energetic decadal and multi-decadal atmosphere/ocean interactions [see Latif, 1998, for a re-

Copyright 1998 by the American Geophysical Union.

Paper number $1998 \mathrm{GL} 900162$.

0094-8276/98/1998GL900162\$05.00 view therein]. Many of these studies suggest fairly complex modes of variability based on either internal ocean dynamics [Delworth et al., 1993] or a coupled atmosphere/ocean interaction [Saravanan and McWilliams, 1997; Weng and Neelin, 1998; Grötzner et al., 1998]. Coupled or ocean-only modes of variability are of interest because they usually elevate the predictability over a white noise (atmosphere) - red noise (ocean) system [Hasselmann, 1976; Battisti et al., 1995]. Here we examine the existence of a preferred ocean time scale by analyzing an ocean model's SST response to an NAOlike wind forcing.

\section{Numerical Experiments}

\subsection{The Model}

We have employed an ocean general circulation model which spans the Atlantic Ocean between $30^{\circ} \mathrm{S}$ and $73^{\circ} \mathrm{N}$ with a horizontal resolution of $2^{\circ}$ by $2^{\circ}$. The model has 30 fixed vertical levels, 13 of which are distributed over the upper $1000 \mathrm{~m}$ with decreasing vertical resolution from 15 to $100 \mathrm{~m}$. Below $2000 \mathrm{~m}$ depth, the vertical resolution is $250 \mathrm{~m}$ with a variable lowest layer thickness. The basin geometry and bathymetry are resolved on the model grid.

The model solves the primitive equations on an Agrid and is forced by climatological monthly mean wind stresses. Temperature and salinity are restored to climatological values over a few grid points near solid walls at the northern and southern ocean boundary. Fresh water fluxes are obtained by restoring the sea surface salinity to a monthly data set with a 30 day relaxation time scale. The surface heat fluxes are determined by a prognostic atmospheric boundary layer model coupled to the ocean model's SST [Seager et al., 1995]. The boundary layer atmospheric temperature and humidity are specified over land but vary over the ocean according to an advective-diffusive balance subject to air-sea fluxes. All other boundary conditions such as the short wave radiation, cloud cover, wind speed, and wind vector are specified at each grid point with monthly resolution.

A simple one and a half layer thermodynamic sea-ice model is coupled between the ocean and atmospheric boundary layer in order to reduce the heat flux in ice covered regions. Unresolved small scale processes are parameterized by a bulk wind driven mixed layer model, 
convective adjustment, and isopycnal thickness diffusion.

First the model was integrated for 100 years. The winter SST differences between the model and observations are typically less than $1^{\circ} \mathrm{C}$ with the exception of the Gulf Stream region. Mixed layer depths are maximum during late winter in the Labrador Sea with a quite realistic distribution throughout the subpolar gyre.

Then NAO-like wind anomalies were added to the climatological forcing with sinusoidal modulations of 2,4 , $8,12,16,24,32$ and 64 year period. The wind anomalies were only applied between November and April, when the NAO explains most of the sea level pressure variance [van Loon and Rogers, 1978]. Each experiment was run over several forcing cycles so as to obtain a quasi-equilibrium upper ocean model response.

\subsection{The NAO anomaly fields}

Using the winter mean NAO index [Hurrell, 1995], we constructed NAO-like anomaly fields by linearly regressing the index against the November through April NCEP NCAR Reanalysis (1958-1998) wind speed, wind vector and wind stress fields. The resulting wind stress anomalies show enhanced westerlies during the positive NAO phase accompanied by a weakening of the trade winds (Fig. 1a). The wind speed anomalies reveal a banded structure with significant large scale variability throughout the Atlantic (Fig. 1b).

\section{Results}

The in-phase SST response (Plate $1 ; \mathrm{a}, \mathrm{d}, \mathrm{g}, \mathrm{i}$ ), which we define as the SST anomaly during a NAO+ phase, shows significant similarity between the periods $(4,12$, 32) south of $30^{\circ} \mathrm{N}$ and closely resembles the three banded structure of the NAO-SST covariance found in observations (Plate 1; a) [Bjerknes, 1964; Cayan, 1992; Kushnir, 1994]; with cooling in the subpolar ocean, warming in the Gulf Stream region, and again cooling in the subtropics. The similarity amongst the different forcing periods suggests a fast and direct response of the subtropical ocean to the wind anomaly fields.

The SST response in the subpolar gyre, however, shows a more complex signal. In particular, the region near $50^{\circ} \mathrm{N}$ shows a reversal in sign with cooling up to decadal forcing periods and warming on longer time scales.

Next, we examine the thermal inertia or 'memory' of the ocean by computing the SST anomaly in-quadrature to the forcing (Plate $1 ; \mathrm{b}, \mathrm{e}, \mathrm{h}, \mathrm{k}$ ), which we define as a $90^{\circ}$ phase lag after the $\mathrm{NAO}+$ phase. Plate $1 \mathrm{~b}$ shows the in-quadrature observed SST response, which was constructed by subtracting those years which indicate a transition into an $\mathrm{NAO}+$ phase $(1945,52,62,76,83)$ from those years which indicate a transition out of an NAO + phase $(1948,58,71,72,81,91)$. The in-quadrature SST response exhibits significant surface temperature anomalies only poleward of $35^{\circ} \mathrm{N}$. The maxima are of a similar magnitude but shifted downstream of the in- phase maximum response. This suggests that ocean advection along the Gulf stream extension might be an important mechanism [Hansen and Bezdek, 1996]. Sutton and Allen [1997] have shown that propagating winter SST anomalies can be traced along a transect between Florida and Scotland. The observed SST evolution along such a path (Plate $1 ; \mathrm{c}$ ) shows a complex structure with some indication for propagating anomalies. Some of those features are similar to the idealized run with a forcing period of 12 years (Plate $1 ; f$ ). It is however important to notice that the runs show dramatically different overall 'propagation' speeds. Over the first $3000 \mathrm{~km}$ the anomalies move swiftly eastward with phase speeds of about $5 \mathrm{~cm} \mathrm{~s}^{-1}$. From then on 'propagation' speeds vary and are set by the forcing frequency multiplied with the distance between Florida and Scotland. This variable 'propagation' speed is not consistent with the upper ocean velocities which change by no more than $30 \%$.

In order to quantify the frequency-dependent response of the upper ocean, we calculate the standard deviation of March SST anomalies for three regions and plot them versus the forcing period (Fig. 2). The tropical/subtropical North Atlantic shows a weakly red response with increasing SST variance for lower forcing frequencies. In the Gulf stream region we find a slightly increased variance in the decadal band. The subpolar
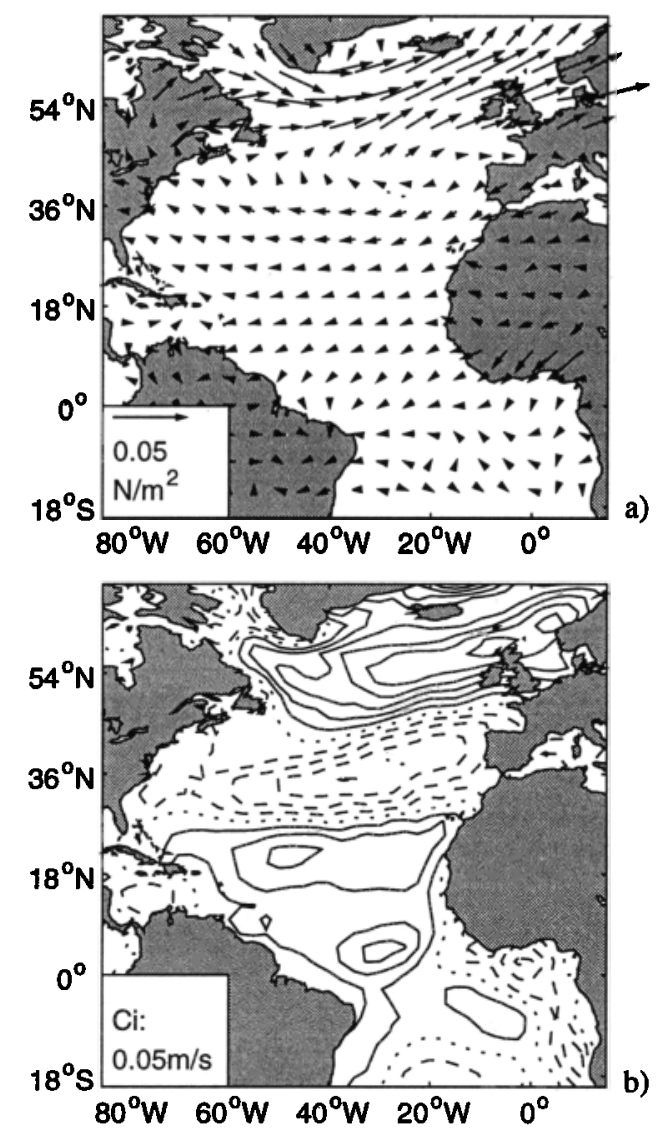

Figure 1. a) Wind stress anomalies per NAOI unit obtained by regressing the November-April NCEP NCAR Reanalysis (1958-1998) against the Hurrell NAO index (see text for details); b) same as a) but for wind speed. 

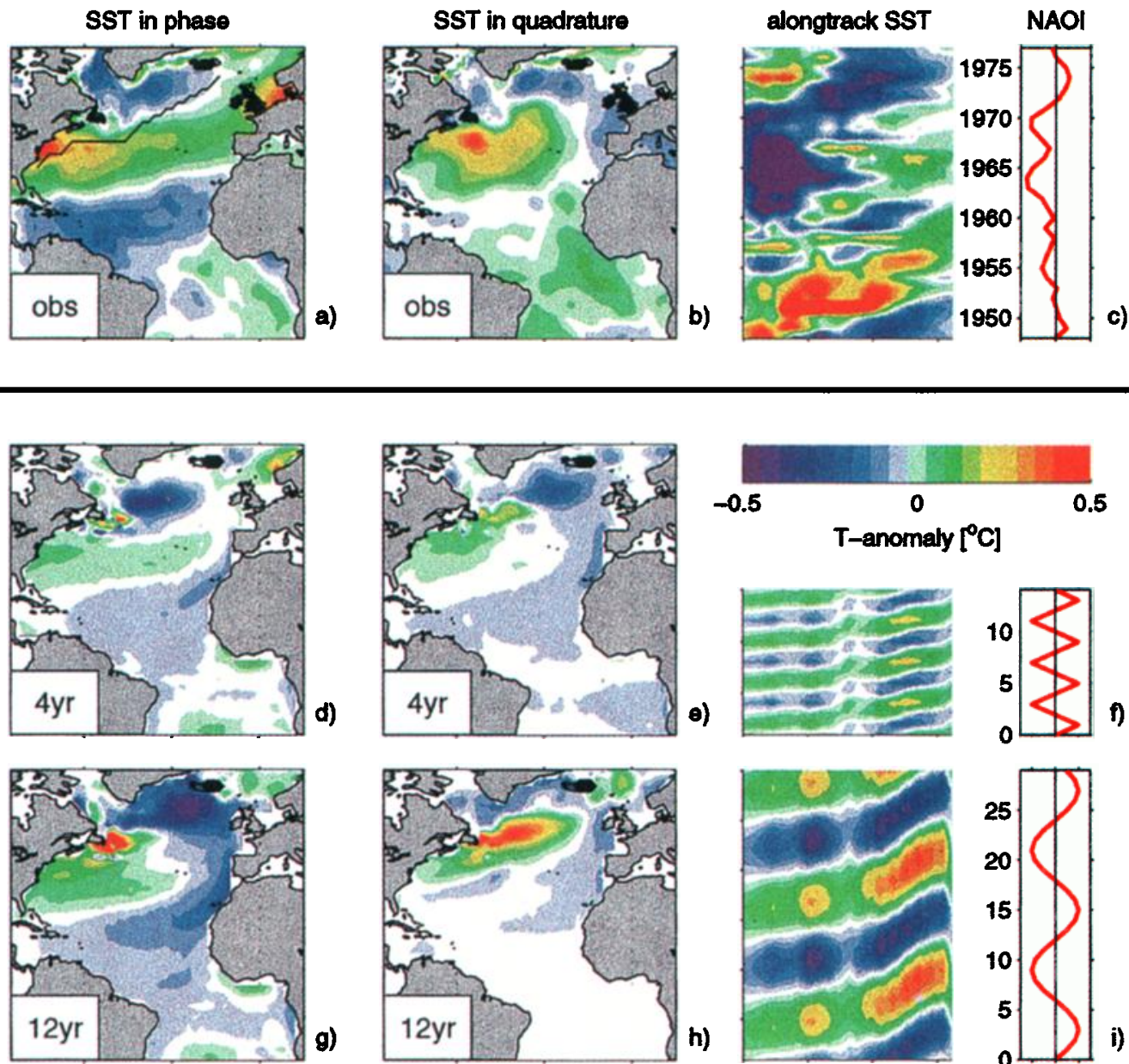

e)
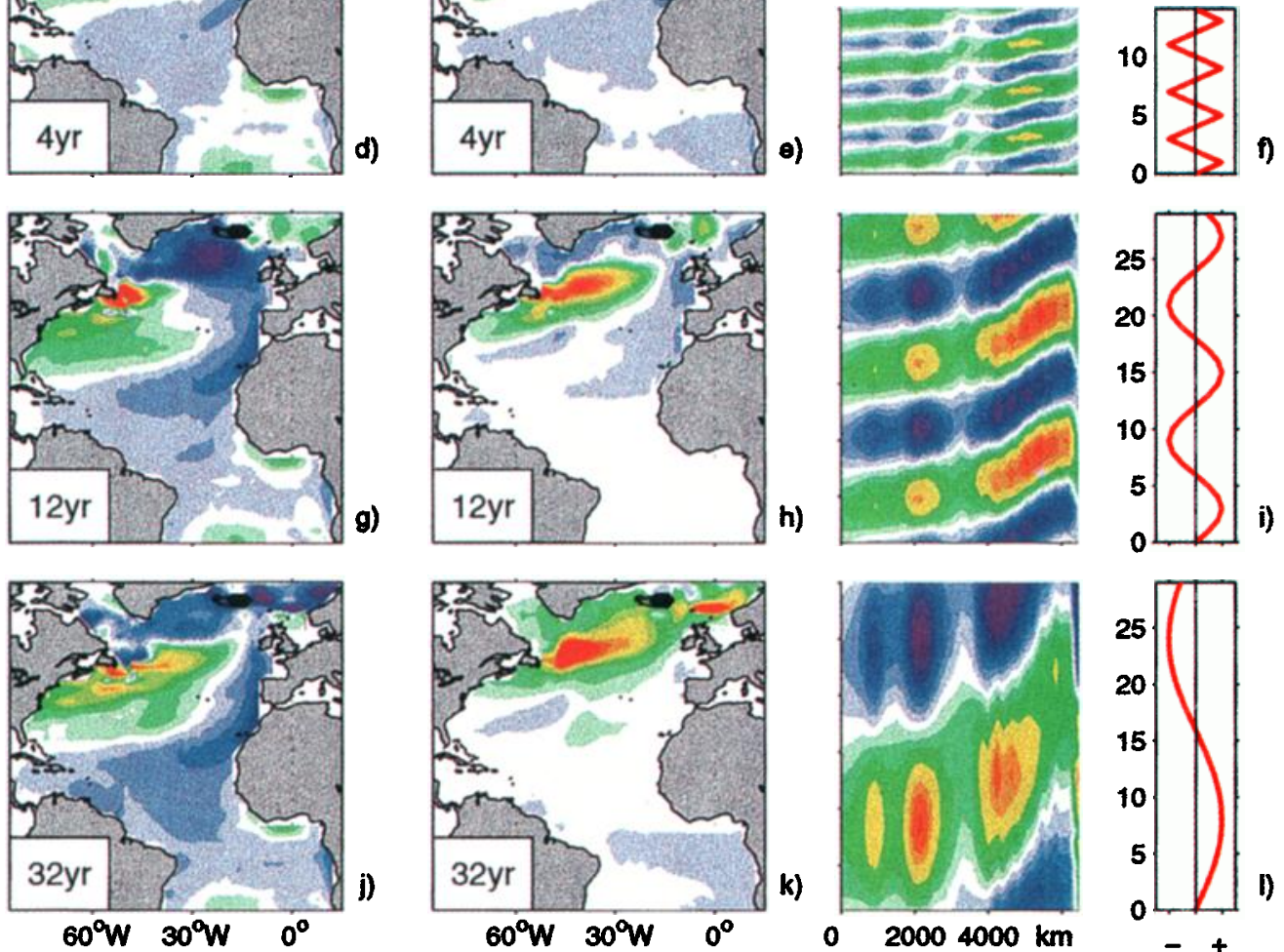

Plate 1. a) Observed in-phase SST response during the NAO+ phase based on the COADS SST data set (see text for details); b) In-quadrature response with a $90^{\circ}$ phase lag after the NAO+ phase (see text for details); c) SST anomalies as a function of distance and time along a path from Florida to Scotland (depicted in a) by a solid black line). The next three rows display the 4,12, and 32 year ocean model SST response. The first column $(\mathrm{d}, \mathrm{g}, \mathrm{j})$ shows the annual mean SST response in phase with the NAO index. The middle column $(\mathrm{e}, \mathrm{h}, \mathrm{k})$ shows the in-quadrature response. The right column $(f, i, l)$ displays the model SST anomalies as a function of distance and time as in c).

gyre, however, shows a broad maximum response in the decadal band between the 8 to 24 year period. The maximum response is centered at the 12 year period but depends somewhat on the location used for the averaging.

\section{Conclusions}

We have investigated the ocean response to NAO-like forcing as a function of frequency and found three main results:
First, the SST response in the subtropical/tropical Atlantic was largely in phase with the applied NAO forcing. This suggests a rather rapid oceanic response to the atmospheric forcing with little contribution from slow ocean dynamics. The absence of a strong lagged SST response diminishes the possibility for delayed oscillator type coupled atmosphere-ocean modes of variability arising from the subtropical ocean.

Second, the Gulf stream extension region is providing significant amounts of memory to the system which results in strong SST anomalies in-quadrature to the 


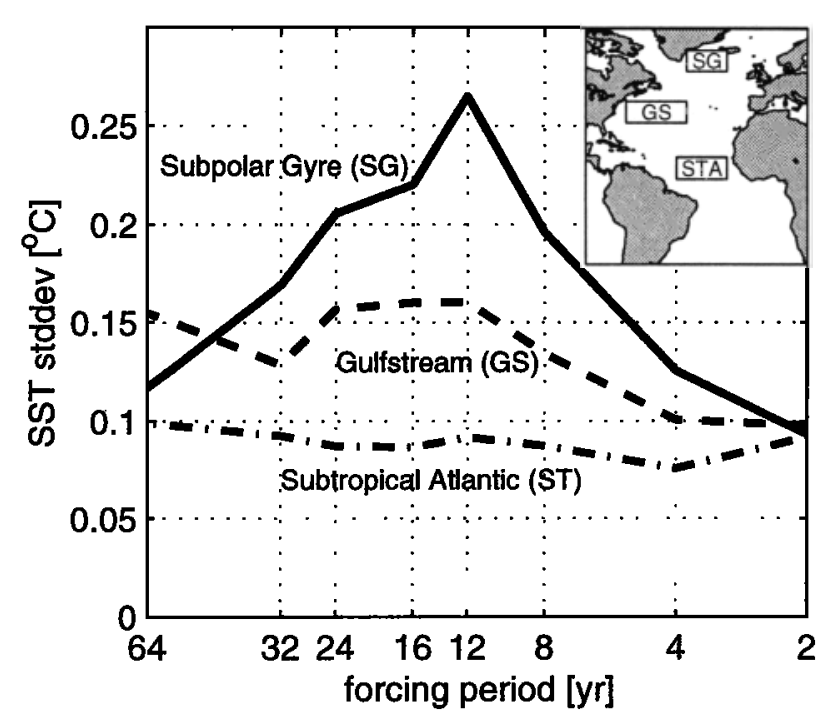

Figure 2. Model winter SST standard deviation as a function of forcing period for the Gulf Stream, Subtropical Atlantic, and subpolar gyre regions (see map for locations). The selected regions are: Gulf Stream $\left(31^{\circ}-41^{\circ} \mathrm{N}, 70^{\circ}-40^{\circ} \mathrm{W}\right)$, tropical/subtropical Atlantic $\left(5^{\circ}-15^{\circ} \mathrm{N}, 44^{\circ}-20^{\circ} \mathrm{W}\right)$ and the subpolar gyre $\left(55^{\circ}-65^{\circ} \mathrm{N}, 40^{\circ}-30^{\circ} \mathrm{W}\right)$.

forcing. Deep mixed layers increase the available upper ocean heat capacity by generating deep temperature anomalies which get re-exposed to the sea surface during subsequent winter seasons. Those SST anomalies seem to migrate to the northeast in much the same way as diagnosed from the observations [Hansen and Bezdek, 1996; Sutton and Allen, 1997]. However, the overall cross basin 'propagation' speed depends strongly on the forcing frequency and is not set by the advection speed of the upper ocean. This suggests that they are actively forced and destroyed by atmosphere-ocean interactions and not just passively drifting with the ocean currents.

Third, there is some indication for a maximum SST response in the subpolar gyre in a broad frequency band between the 8 to 24 year period. This, together with the finding that the in-phase SST response changes sign near $50^{\circ} \mathrm{N}$ between the high and low frequency forcing, raises an interesting possibility for a decadal atmosphere-ocean mode: If the atmosphere was responding to a cold subpolar SST anomaly with a preference for the $\mathrm{NAO}+$ phase, then an initial positive feedback would be established. Over time, a prolonged $\mathrm{NAO}+$ phase warms the upper subpolar ocean and the positive feedback would be destroyed. A continued subpolar warming might then force the atmosphere into a preferred NAO - phase which then could lead to a self sustained oscillation of roughly decadal period. While an intriguing possibility, the current evidence for a significant and robust atmospheric response to midlatitude SST anomalies is inconclusive [Kushnir and Held, 1996]. However, the evidence is based primarily on atmospheric model calculations with significant inher- ent uncertainty and conflicting results between different models.

Acknowledgments. M. Visbeck, H. Cullen and N. Naik acknowledge support from NOAA G. Krahmann obtained funding for a one year postdoctoral fellow ship at LODYC, Paris from the EEC Millennia Project. Y. Kushnir, R. Seager and $G$. Reverdin provided helpful suggestions concerning the project and the manuscript. This is Lamont contribution \# $\mathbf{5 8 7 5}$

\section{References}

Battisti, D., Bhatt, U. and M. Alexander, A modeling study of the interannual variability in the wintertime North Atlantic ocean, J. Clim., 8, 3067-3083, 1995.

Bjerknes, J., Atlantic air-sea interactions, Adv. Geophys., 10, 1-82, 1964.

Cayan, D., Latent and sensible heat flux anomalies over the northern oceans: The connection to monthly atmospheric circulation, J. Clim., 5, 354-369, 1992.

Delworth, T., Manabe, S. and J. Stouffer, Interdecadal variations of the thermohaline circulation in a coupled oceanatmosphere model, J. Clim., 6, 1993-2011, 1993.

Grötzner, C., Latif, M. and T. Barnett, A decadal climate cycle in the North Atlantic Ocean as simulated by the ECHO coupled model, J. Clim., in press, 1998.

Hansen, D. and H. Bezdek, On the nature of decadal anomalies in the North Atlantic sea surface temperature, J. Geophys. Res., 101, 8749-8758, 1996.

Hasselmann, K., Stochastic climate models Part I: Theory, Tellus, 6, 473-485, 1976.

Hurrell, J., Decadal trends in North Atlantic Oscillation: Regional temperatures and precipitation, Science, 269, 676-679, 1995.

Hurrell, J., and H. van Loon, Decadal Variations in Climate associated with the North Atlantic Oscillation, Clim. Change, 36, 301-326, 1997.

Kushnir, Y., Interdecadal variations in North Atlantic sea surface temperature and associated atmospheric conditions, J. Clim., 7, 141-157, 1994.

Kushnir, Y., and I. M. Held, Equilibrium response to North Atlantic SST anomalies, J. Clim., 9, 1208-1220, 1996.

Latif, M., Dynamics of Interdecadal Variability in Coupled Ocean-Atmosphere Models, J. Clim., 11, 602-624, 1998.

Saravanan, R. and J. McWilliams, Stochasticity and spatial resonance in interdecadal climate fluctuations, J. Clim., 10, 2299-2320, 1997.

Seager, R., Blumenthal, M., and Y. Kushnir, An advective atmospheric mixed layer model for ocean modeling purposes: Global simulation of surface heat fluxes, J. Clim., 8, 1951-1964, 1995.

Sutton, R., and M. Allen, Decadal predictability of North Atlantic sea surface temperature and climate, Nature, 388, 563-567, 1997.

van Loon, H., and J. C. Rogers, The seesaw in winter temperatures between Greenland and northern Europe. Part I: Winter, Mon. Weath. Rev., 104, 365-380, 1978.

Wallace, M., and D. Gutzler, Teleconnections in the geopotential height fields during the Northern Hemisphere winter, Mon. Weath. Rev., 109, 784-812, 1981.

Weng, W., and J. D. Neelin, On the role of oceanatmosphere interaction in midlatitude interdecadal variability, Geophys. Res. Lett., 25, 167-170, 1998.

Martin Visbeck, Heidi Cullen, Gerd Krahmann and Naomi Naik, Lamont-Doherty Earth Observatory of Columbia University, Palisades, NY 10964. (e-mail: visbeck@ldeo.columbia.edu)

(Received June 26, 1998; revised September 09, 1998; accepted October 20, 1998.) 